Now the vessels of these two serous membranes have quite sufficient communication with each other, through those of the intervening fibrous tissue, to render it likely that any lesion severe enough-wide enough and deep enough-to involve a large proportion of one network, will be pretty sure to derange the subjacent (and dependent) vessels of the fibrous tunic, and so to affect the other. It is, indeed, almost the old story of the one spur which the butcher found sufficient to extort speed from his horse. One side is almost certain to keep pace with the other.

That the pericardium affects the pleura oftener than the pleura affects the pericardium depends, I think, partly on considerations, anatomical as well as pathological, with which I shall not trouble you now. Much more, however, on the way in which the violent and incessant pressure of the excited heart acts on the physical circumstances of the deposit; squeezing it, as it were, into, and through, the very interstices of the fibrous tissue; and especially making its rapid alterations of consistence a means of exerting a still more powerful pressure on the deeper strata of the inflamed fibres, and on the serous membrane beyond them. The secondary inflammation thus lit up, is rarely, whether pleural or pericardial, accompanied by much effusion of liquid. In other words, the inflammation is generally dry and adhesive.

With many exceptions and fluctuations, the rubbing sound of the inflamed pericardinm is usually audible in two stages of the disease: before the visceral and parietal surfaces of the membrane are separated by much liquid; and, again, after that liquid has been absorbed. But the slower changes of pleural lymph, and the wider and more powerful movement of the lung as contrasted with that of the heart, constantly pull out the softer substance of the adherent pleuritic mass-spin it into downright threads. The tugging and twitching of the inflamed pleural surface thus implied, is often a very painful process to the patient; and, indeed, unless appreciated and remedied, the apparent relapses it implies are (as they would have been in this case) a serious embarrassment. Our patient was terribly frightened by them; and almost refused to be relieved of apprehensions, the grounds for which were so painful and urgent.

Lastly, he illustrates an uncertainty which I do not hesitate to confess. His whole life hangs on the answer to the question - "What is the state of the cardiac valves?" Really I do not know. Comparing the pulse and the sounds, I am sure that the semilunar valves have got off substantially unhurt. I believe that the mitral are also little affected. Indeed I should conjecture that they are essentially untouched. But after watch. ing and listening at large numbers of such cases, and often following them up many months and years after they have ceased to require any medical relief, $I$ much doubt whether it is always possible to distinguish a pericardial from an endocardial murmur, especially when of recent origin. Here the bulk of the soft bellows-sound is undoubtedly outside the heart. More than this, however, it is impossible to assert.

\section{PHLEGMONOUS ERYSIPELAS OF THE LEFT UPPER AND LOWER EXTREMITIES IN A CHILD THREE WEEKS OLD.}

\section{By G. M. BEALE, Eso}

ON the 9th instant I received a message that Mrs. P___'s child was ill, with an injunction to attend immediately. On seeing the little patient, the countenance indicated great suffering, and the pulse was rapid. From the history, it appeared that the child, previously healthy, had been cross for a few days, but nothing was apprehended until the mother accidentally discovered the swelling in the arm just prior to her sending for me. On examination, the swelling and cedema of the extremities were very apparent, and the temperature was considerably increased; but the most careful examination failed to give evidence of fluctuation. The viscera were healthy. Warm applications were ordered to be applied locally, a mix. ture of hyoscyamus and nitric ether to be taken every two or three hours, and a little grey-powder and rhubarb immediately, the bowels being confined.

March 10th.-Face more blanched and anxious; the pulse weaker and more rapid; in short, all the symptoms aggravated. The presence of matter both in the arm and leg was now clearly indicated. I at once decided upon freely laying open the affected parts, but on second consideration thought it better to make a number of small incisions, rather than the long ones I at first intended, both on acconnt of the age of the patient and the hæmorrhage that might ensue from the more heroic treatment. The friends having consented, the punctures were made with an ordinary lancet, and a considerable quantity of pus and serum escaped from the various openings; but notwith. standing the free administration of wine, chloric ether, and ammonia, the child died twelve hours after the operation, and less than forty-eight hours after the swelling was first observed.

Avenue-terrace, New-road, Hammersmith, March, 1860.

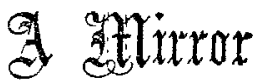

OF THE PRACTICE OF

\section{MEDICINE AND SURGERY IN THE}

\author{
HOSPITALS OF LONDON.
}

Nulla est alia pro certo noscendi via, nisi quam plurimas et morborum et dissectionum historias, tam aliornm proprias, collectas habere et inter se comparare.-Moвgagni. De Sed. et Caus. Morb., lib. 14. Proœmium.

\section{CHARING-CROSS HOSPITAL.}

CONGENITAL DISLOCATION OUTWARDS OF THE LEFT PATELLA IN A KNOCK-KNEED LEG.

(Under the care of Mr. CANToN.)

Is knock-kneed, flabby people, the surgeon has occasionally to reduce a dislocated patella, which may have been displaced outwards owing to the natural weakness and laxity of the parts around the knee-joint. Sudden muscular contraction in the same class of individuals is pronounced to be the most common cause of the outward dislocation, and direct violence has been known to drive the bone out of its natural position. A displaced patella is not observed in our hospitals as a permanent deformity nor as a congenital vice, except in very rare instances. One of these we lately had the opportunity of carefully examining, at the above hospital, under Mr. Canton's care, the particulars of which are given below. The deformity seems to have been congenital, but in the history there is nothing to show the presence of any cerebral or spinal disease, although the shape of the boy's head is somewhat peculiar. We mention this fact, as it is one of some significance in relation to congenital defects of the patella. On searching many of the standard works on Surgery for examples similar to Mr. Canton's, we find the subject noticed only in Mr. Brodhurst's book on "Clubfoot," and his remarks are of some importance in relation to the present case. It appears that in severe forms of congenital varus, in which there is malformation of the tarsal bones, there is generally found to co-exist some abnormality of the brain or spinal cord. Mr. Brodhurst observes that, "In these cases, and also when distortion is less complicated, the patella is not unfrequently retracted above its usual position : it may be drawn up on the outer side of the thigh to the extent of from two to three inches." (p. 32.) Besides the dislocation, the same writer has occasionally observed the bone to be scarcely more than elementary in its development. Now, in Mr. Canton's patient, there was no malformation of the foot, but slight knock-knee of the left leg; and it is just possible that slight nervous defects in early uterine life may bave produced the deformity -an opinion which is suggested by the abnormal shape of the head, although in all other respects (beyond a strumous diathesis) the boy was quite well. There was not any retraction of the patella upwards, but solely dis. placement outwards, as represented in the drawing. The dislocation of the bone was noticed at birth, but was not believed to be of any importance; and now the external condyle has become so worn away that a cure is beyond the reach of sur. gical art. However, the case is well worthy, from its extreme rarity, of being placed on record. 